\title{
Leaders as Coaches
}

\section{Dr. Meg Handley, Pennsylvania State University, University Park}

Meg Handley is currently the Associate Director for Engineering Leadership Outreach at Penn State University. Previously, Meg served as the Director of the Career \& Corporate Connection's office at the Smeal College of Business at Penn State University. Meg completed her PhD in Workforce Education at Penn State, where she focused on interpersonal behaviors and their impact on engineering leadership potential.

Meg is a board certified coach with experience in developing students' leadership and professional competencies through teaching and one-on-one coaching. She is most interested in developing student knowledge of leadership to impact their successful transition to the workplace.

\section{Dr. Dena Lang, Pennsylvania State University, University Park}

Dr. Lang is the Associate Director of the Engineering Leadership Research Program at Penn State University. She holds a BS in Mechanical Engineering from West Virginia University, an MBA from Johns Hopkins University, and a PhD in Kinesiology with a focus on Biomechanics from Penn State University. Dr. Lang's previous professional experiences and research interests range from mechanical engineering facilities design to research that applied engineering and molecular biology approaches to the study of the skeletal response to mechanical loading. As a Mechanical Engineer, she worked on facility design projects involving mechanical systems that included heating, ventilation, air conditioning, and energy conservation systems, as well as R\&D of air conditioning equipment for Navy ships. Additional research interests have included the investigation of relationships among components of the indoor environment, occupants, and energy usage. Specifically, the effects of the indoor environment on occupant health and well-being and in parallel, how socially-mediated energy-saving strategies can increase awareness of energy use and/or increase energy saving behaviors. Dr. Lang's current research interests focus on identifying, assessing, and developing key skills, knowledge, attitudes, and other intrinsic and extrinsic factors required for engineers to effectively lead others, particularly other engineers and across cultures.

\section{Prof. Andrew Michael Erdman, Pennsylvania State University, University Park}

Andrew M. "Mike" Erdman received his B.S. in Engineering Science from Penn State and his M.S. from USC. At Rocketdyne (Pratt \& Whitney), he helped design the Space Shuttle. As manager of Reactor Safety Analysis, Experimental Engineering, and Fluid Dynamics Technology at KAPL (Bechtel), he conducted research for Naval Reactors. He currently serves as the Walter L. Robb director of Engineering Leadership and as a Professor of Practice in SEDTAPP and Engineering Science at Penn State. Erdman has chaired the local Jaycees, Department of Social Services Advisory Council, GE Share Board, and Curling Club; and served on the Human Services Planning Council, United Way, Chamber of Commerce, and Capital Fund Drive Boards of Directors. Erdman has lectured on leadership topics at Penn State and RPI. He served as a recruiter (25 years) for GE and Lockheed Martin, on the Penn State College of Engineering Advisory Council, an Alumni Advisory Board, and as the President of the College of Engineering Alumni Society. Affiliations include Fellow of ASME, member of ASEE, AIAA, the Penn State Alumni Association, Centre County Chapter Board of Directors, President's Club, Nittany Lion Club. He has been honored with a LMC Leadership Award, GE Phillippe Award, PSEAS Outstanding service award, Jaycee International Senatorship, and an ESM Centennial Fellowship.

\section{Dr. John Jongho Park, Pennsylvania State University, University Park}

Dr. Park is an assistant research professor in the Engineering Leadership Program at Penn State University. There is four interrelated areas of inquiry characterize Dr. Park's scholarship: psychological attributes, professional identity development, group processes, and leadership development. Particularly, he examines how possible future-self influences individuals' learning, academic motivation, and career trajectory. The major population he primarily focuses on is STEM undergraduate and graduate students. He has received extensive qualitative and quantitative methodological training in the area of educational 
psychology. He acquired a Bachelor's of Science in Human Resources Management and a Masters of Educational Technology from California State University, Long Beach, and a Master's of Program Evaluation and a Doctorate of Philosophy from the University of Texas at Austin. Prior to joining the Penn State University, he worked as a research fellow and program evaluator at University of Michigan. Also he taught an "individual learning skills" as an assistant instructor in the University of Texas at Austin for five years. 


\section{Engineers as Leader-Coaches}

\section{Background}

Demands on engineering leaders require an ability to navigate solutions for ill-defined problems against tight deadlines, to effectively deal with global challenges, and to work within complex and diverse social-technical team environments [1]-[3]. Many organizations have adopted coaching programs to address these challenges in leader performance and improve effectiveness within the work place [4], [5]. The application of coaching skills is essential for effective managerial leaders in today's challenging work environment [6]. One definition of coaching positions the coach as a facilitator of growth and development for the coachee: "..equipping people with the tools, knowledge, and opportunities they need to develop themselves and become more effective" [7].

However, coaching can be seen as both a function and a competency [8]. As a function, a person receives individual coaching for personal development. This type of coaching is typically labeled as executive coaching, life coaching, or career coaching, used for selected individuals within an organization. Coaching as a competency is an example of a leader/manager employing coaching behaviors to impact team effectiveness and employee development. Recent literature describes this form of coaching as managerial coaching in which a leader/manager creates an environment focused on learning, growth and adaptation; forgoing traditional directive and coercive behaviors for teaching, influencing, and questioning behaviors [9], [10].

Leader-as-coach, or managerial coaching as described in research, assumes a balance between directive and participatory behaviors and focuses on self-directed learning by the employee [11]. In managerial coaching, workplace interactions and experiences between employees and managers serve as a catalyst for learning [12]. A managerial coach forgoes habitual directive behaviors in lieu of coaching competencies that motivate and inspire learning and development of the employee. Managerial coaching behaviors have been linked to performance success [11], [13]-[19], and increased motivation, personal development, and retention [14], [17]. Behaviors associated with managerial coaching include supporting and helping, providing feedback, questioning, active listening, communicating openly, building perspective, and letting go of control [9], [11], [19], [20].

In the engineering context, coaching has emerged as an important aspect of engineering leadership [3], [21]. Industrial warehouse managers practicing coaching competencies was a highly significant predictor of employee warehouse performance [11]. Studies focused on project management concluded that coaching competencies were essential behaviors for successful project managers [22], [23]. Leadership behaviors for systems engineers include coaching as a theme for effective leadership [24]. Design programs have implemented coaching elements in courses focused on building empathy and user centered design to impact the effectiveness of software and product development engineers [25], [26]. Further, the engineering context, ripe with ill-defined problems, requires leaders who can adapt to different problemsolving mindsets and diverse teams to create innovative solutions [23], [27]. Coaching competencies require leaders to adapt to differences in employees to impact learning and personal development [23]. Competence in coaching impacts innovative thinking and creativity 
through behaviors such as questioning the status quo, fostering new perspective taking, and learning from failures [28]. "Coaching surfaces creative approaches to solving conflicts that often arise during change, and it enables organizations to identify and incorporate new ideas, process, or procedures that drive innovation" [28] pg. 157.

Engineering leadership development programs seeking to develop the leadership skills needed for engineers to be successful in industry must also consider coaching competencies as an important element of engineering leadership curriculum. The purpose of this paper is to describe a coaching course implemented into an engineering leadership development program and to identify the leadership behaviors observed in coaches practicing coaching skills.

\section{Coaching in the Classroom}

Literature reporting the implementation of coaching in engineering classrooms demonstrates curricular designs and learning outcomes with positive student outcomes. Stettina, Zhao, Back, and Katzy [26] implemented coaching practices in short stand-up meetings that focused on asking powerful questions to reflect and assess progress on project deliverables. Using a quasiexperimental approach, the researchers found that adding coaching into small stand-up meetings provided for successful information exchange and increased student satisfaction in course learning. Knight, Poppin, Seat, Parsons, and Klukken [29] looked at the impact on team orientation and team task performance of senior design course teams with graduate level coaches. The teams with graduate level coaches reported higher levels of team orientation throughout the semester as opposed to teams who did not receive the coaching. These findings suggest that coaches impacted engineering team environments specifically pertaining to interpersonal interactions. Findings did not show an impact on team task performance compared to non-coached teams. Although each of these studies were small, they are examples of course designs where coaching can be explored as an influence on engineering work.

The transference of coaching skills within a classroom setting centers on an experiential learning orientation and an andragogic (learner-centered) approach. Based on Kolb's [30] model, experiential learning theory posits that the learning process is continuous and is grounded in experiences which then provide for observations and reflections. The curriculum design for the coaching course in this study positions the students to learn through experiencing the practice of coaching with both teams and individuals. Further, coaching is based on an andragogic approach where the learner is the center of the experience, being independent, and who sets the direction of their own learning [8], [31]. The classroom environment for coaches should model this approach to ensure coaches experience a learner centered classroom to then model this type of learning in their coachee interactions. Additionally, traditional notions of leadership tend to position leaders as the knowledge bearers who provide solutions to team challenges and handle all problems. These societal-expectations of leaders are contrary to leader-as-coach practices and have to be deconstructed in a coaching environment. O'Flahtery [8] suggests the importance of a coaching skill transference that fosters a paradigm shift. This shift requires leaders to refrain from solving-problems and providing answers and instead foster learning through powerfulquestioning. This allows the employee the space and time to discover new possibilities, generate new options, and fosters individual learning [8]. The insights from this literature helped to inform the structure of the engineering coaching course. 


\section{Methods}

\section{Course Design}

The engineering coaching course, labeled ENGR 496, was designed as a higher-level course in an 18-credit engineering leadership development minor within a large engineering college. Students eligible for the ENGR 496 course previously completed ENGR 408Leadership Principles, the entry-course into the minor, or ENGR 422, a cross-cultural virtual teaming course. Both ENGR 408 and ENGR 422 are courses that require a team project, providing for the experiential learning environment by which coaches would practice their coaching skills. ENGR 496 coaches were each assigned two teams in one of the ENGR 408 or 422 classes where they met in person with their teams throughout the semester. The ENGR 496 course is a flipped course where students identify and describe effective coaching skills and then participate in classroom activities to begin practicing coaching behaviors and formulating their coaching approaches with teams and individuals. This knowledge transfer process occurs over a three-week period prior to their first meetings with their coaches. The andragogic approach to the course requires the coaches to observe and meet with assigned teams outside of the classroom, applying an experiential and self-directed learning approach for the coach. Coaches rotate through a variety of assignments throughout the semester that follow Kolb's [30] experiential learning cycle. Students repeat activities related to team coaching, such as observing leaders, giving leader performance reviews, and reflecting on their performance as a coach. Student coaches will also be observed throughout the semester by their instructor and then also by their peers. At the end of the semester, coaches are evaluated using a 360 tool, and after completion of a one-on-one coaching session with their instructor, complete a final reflection paper. The 360-review tool provides the data to address the research question for this study: Which leadership approaches, identified from a 360-review tool, are observed in students who practice coaching skills?

The coaching course, opened to all students in the 18-credit leadership minor who had completed pre-requisite courses, was developed in the spring of 2018 and to-date has 27 students who have completed or are currently enrolled in the course. The findings from this study are based on 14 student coaches who have completed the coaching course. Students ranged from juniors to seniors and represented multiple engineering majors. A 360 review was utilized to assess observed leadership approaches of students practicing coaching skills. 360-degree feedback is a method to collect perceptions of leadership behaviors and effectiveness from the viewpoints of peers, direct reports, supervisors, and a self-report [32]. The instrument utilized in this study was the Everything DiSC $363^{\circledR}$ based on eight leadership approaches (see figure 1). Raters are provided 72 behavior statements and asked to rate how often the leader demonstrates the behaviors from 1 (never or almost never) to 7 (always or almost always). The measures of the Everything DiSC $363^{\circledR}$ assessment demonstrate good-to-excellent internal consistency and outstanding inter-rater reliability with validity supported through multidimensional scaling and scale intercorrelations [33]. The leadership approaches and practices that are assessed by the Everything DiSC $363^{\circledR}$ are outlined in Figure 1. 
Each student coach practiced coaching techniques during five team coaching meetings spread out through the semester and 10 individual performance reviews. Direct reports, students on the ENGR 408 or ENGR 422 teams, were asked to fill out the Everything DiSC $363^{\circledR}$ at the end of the semester. Peer coaches also completed the survey at the end of the semester based on observing peer coaching performance in the classroom. The instructor observed each peer coach twice; once during a team coaching meeting and once during an individual performance review meeting; and then completed the survey at the end of the semester. The mean scores were calculated on each of the eight leadership approaches to rank the leadership approaches observed in students practicing coaching skills. The study's design is exploratory in nature to assist in improving course design and curriculum related to managerial coaching practices. For these reasons, the Everything DiSC $363^{\circledR}$ approaches and practices (Figure 1) were mapped to managerial coaching behavior models (Table 1) to provide a framework for identifying improvements for the current coaching course discussed in this study.

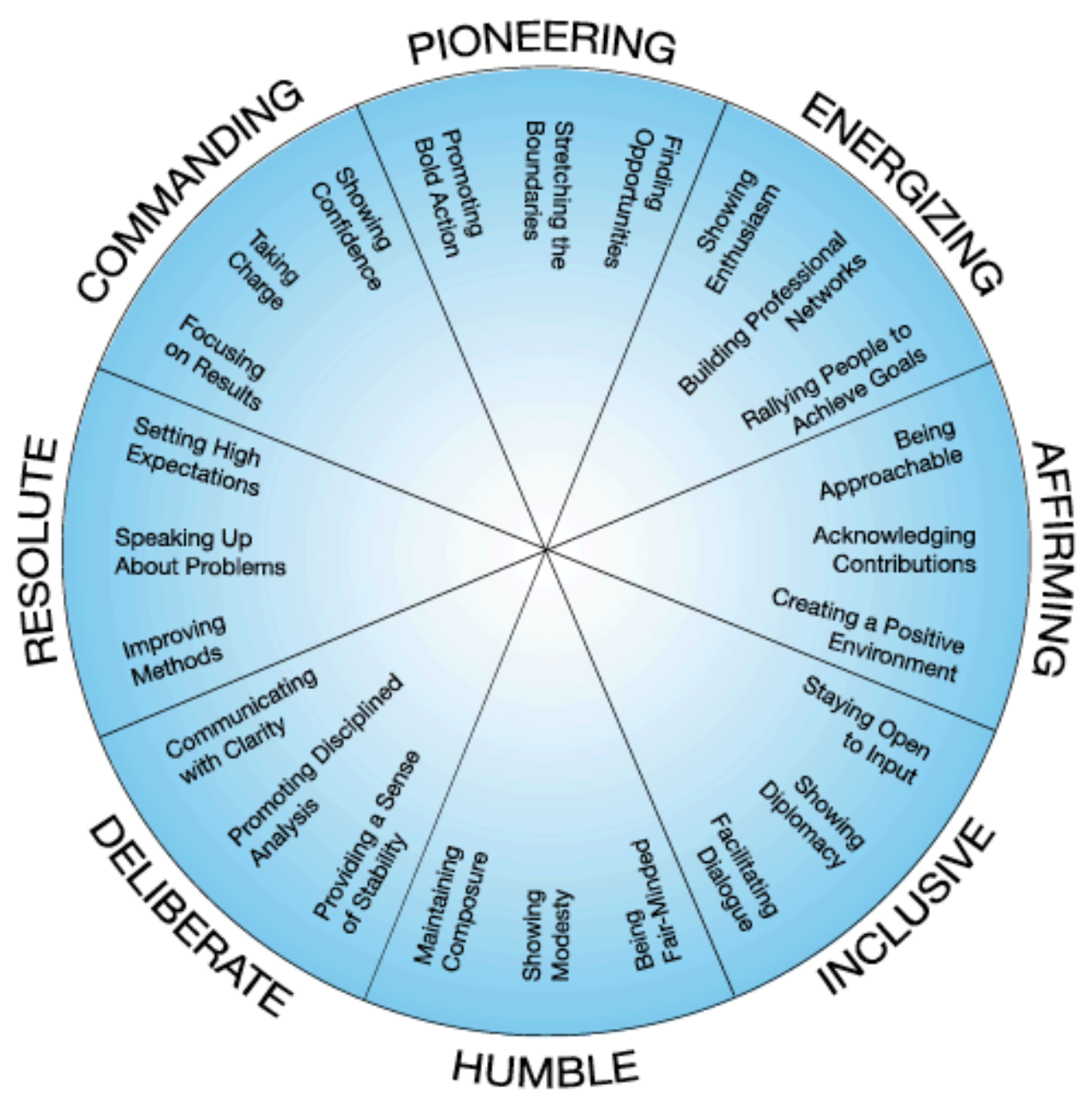

Figure 1. Everything DiSC $363{ }^{\circledR}$ Leadership Approaches and Practices $\odot$ Copyright 2010 by John Wiley \& Sons, Inc. All rights reserved. Used by permission. Everything DiSC $363 \AA$ is a registered trademark of John Wiley \& Sons, Inc., and/or its affiliates in the United States and other countries 


\section{Results and Discussion}

Results from the data analysis reveal inclusive, affirming, and deliberate behaviors as top ranked leadership approaches observed in students practicing coaching skills within this limited sample (see figure 2). The lowest ranked leadership approaches observed in students practicing coaching skills were pioneering, energizing, and commanding.

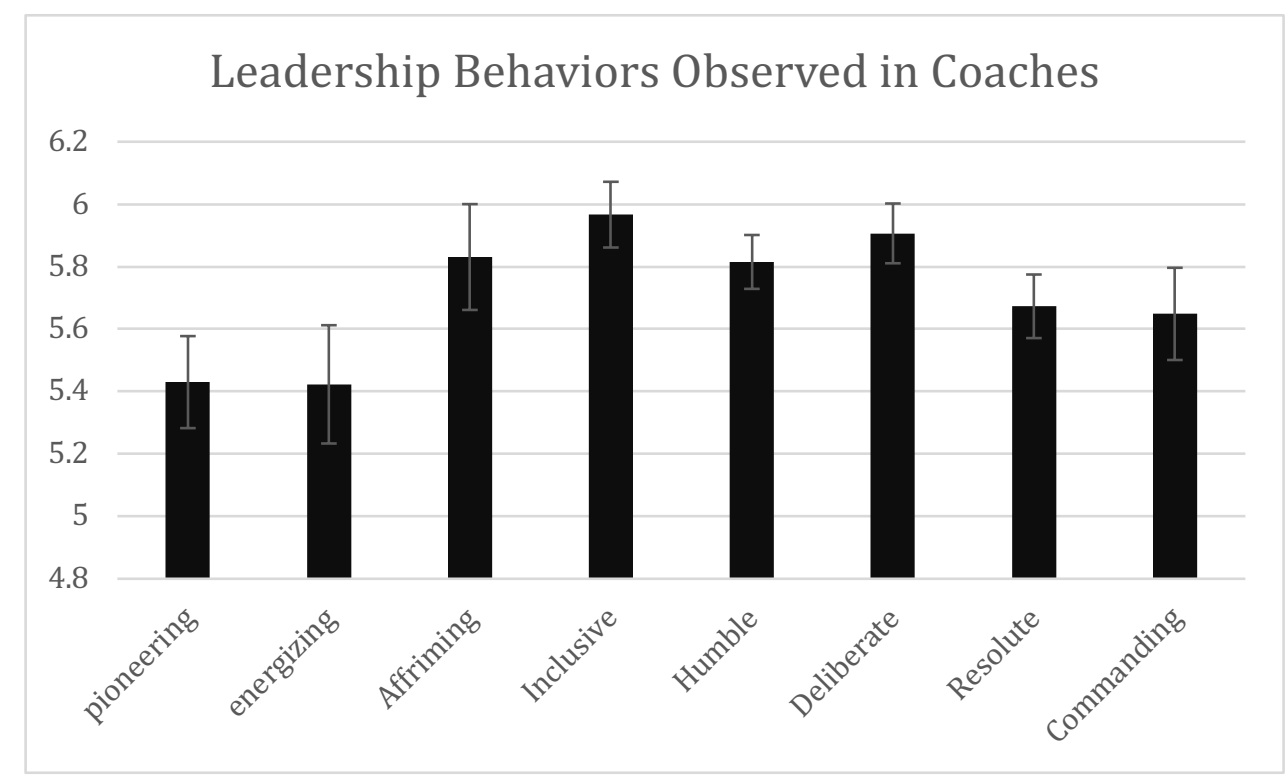

Figure 2. Means of leadership approaches observed in leaders practicing coaching skills

Table 1 maps the leadership approaches from the Everything DiSC $363^{\circledR}$ with empirically developed managerial coaching behaviors. The studies outlined in Table 1, while using different language, have also undergone a comparative analysis determining a high degree of congruency among the behaviors attributed to effective managerial coaching [6]. The top ranked leadership approaches identified in the current study (inclusive, affirming, and deliberate) for leaders practicing coaching skills align with facilitating, caring, informing, advising, and assessing managerial coaching behaviors. The lowest ranked leadership approaches identified in the current study (pioneering, energizing, and commanding) for leaders practicing coaching skills align with empowering behaviors of managerial coaching.

Table 1. Everything DiSC $363^{\circledR}$ Leadership Approaches Mapped to Managerial Coaching Behaviors

\begin{tabular}{|c|l|}
\hline Ellinger and Bostrom, [34] managerial coaching behaviors & $\begin{array}{l}\text { Proposed Everything DiSC } \\
363^{\circledR} \text { leadership approach }\end{array}$ \\
\hline Empowering Cluster & High Pioneering \\
\hline $\begin{array}{c}\text { Question framing to encourage employees to think } \\
\text { through issues }\end{array}$ & \\
\hline Being a resource- removing obstacles & Low Commanding \\
\hline Transferring ownership to employees & Low Commanding \\
\hline Holding back- not providing the answers &
\end{tabular}




\begin{tabular}{|c|c|}
\hline Facilitating Cluster & \\
\hline Providing feedback to employees & High Affirming \\
\hline Soliciting Feedback from employees & High Inclusive \\
\hline Working it out together- talking it through & High Inclusive/High Humble \\
\hline Creating and promoting a learning environment & High Affirming \\
\hline Setting and communicating expectations & $\begin{array}{l}\text { High Resolute/High } \\
\text { Deliberate }\end{array}$ \\
\hline Stepping into other to shift perspective & High Inclusive/High Humble \\
\hline Broadening employees' perspectives & High Inclusive/High Humble \\
\hline Using analogies, scenarios, and examples & \\
\hline Engaging others to facilitate learning & $\begin{array}{l}\text { High Deliberate/High } \\
\text { Energizing }\end{array}$ \\
\hline Beattie [35] managerial coaching behaviors & \\
\hline $\begin{array}{l}\text { Caring- support, encouragement, approachable, } \\
\text { reassurance, commitment/involvement, empathy }\end{array}$ & High Affirming \\
\hline Informing- sharing knowledge & High Deliberate \\
\hline $\begin{array}{l}\text { Being professional- role model, standard-setting, } \\
\text { planning and preparation }\end{array}$ & High Resolute \\
\hline Advising- instruction, coaching, guidance, counseling & High Affirming \\
\hline $\begin{array}{l}\text { Assessing- feedback and recognition, identifying } \\
\text { developmental needs }\end{array}$ & High Affirming \\
\hline $\begin{array}{l}\text { Thinking- reflective or prospective thinking, } \\
\text { clarification }\end{array}$ & High Inclusive \\
\hline Empowering- delegation, trust & High Energizing \\
\hline Developing others- developing developers & High Energizing \\
\hline Challenging employees to stretch themselves & High Pioneering \\
\hline
\end{tabular}

The data reveal three areas of specific interest for the ENGR 496 course. The first being the inclusive, affirming, and deliberate approaches as the top ranked behaviors observed in leaders practicing coaching skills. These align with managerial coaching behaviors of facilitating, informing, caring, advising, giving feedback, and reflecting [34], [35]. A leader acting as a coach facilitates conversations that foster openness to embrace all perspectives to solve problems. This is accomplished through establishing a relationship between the coach and the coachee built on trust, active listening and being present. Students in the ENGR 496 class spend time learning the definition of coaching and in particular, the aspects of an effective coaching conversation. Coaching conversations have a beginning, middle, and end. The beginning focuses on establishing trust, active listening, and powerful questioning centered on clarifying and understanding. Middle and end portions of the coaching conversation align with practices that are included in pioneering and energizing approaches and are discussed in detail in the next section. Throughout the entirety of the coaching conversation, coaches practice letting the coachee lead. This practice allows for the coachee to be at the center the learning experience, setting the direction of their own learning and development.

The second area of interest includes the rankings associated with the pioneering and energizing approaches. Pioneering and energizing approaches were ranked the lowest in 
observing leaders practicing coaching skills. Managerial coaching competencies include behaviors of stretching, challenging, empowering, and developing the coachee, all of which relate to pioneering and energizing approaches [34], [35]. These approaches require the skill of powerful questioning. Powerful questioning encourages coachees to think beyond initial perspectives, to stretch the coachee to think more deeply related to a particular learning experience, to challenge current solutions, and build awareness for personal development. These skills are related to the middle portion of the coaching conversation which focuses on asking powerful questions that create awareness for personal development. Powerful questioning techniques used in the beginning of a coaching conversation are typically clarifying in nature. Powerful questions used in the middle portion of the coaching conversation require more thought and elicit deeper reflection. The end of the coaching conversation also requires challenging and empowering coachees to design actions to address revealed areas for development. Lower rankings in pioneering and energizing approaches reflect a need to better prepare leader-coaches to challenge coachees to reflect more deeply and create action plans and goals to impact personal or team growth and change. Examples that illustrate differences in powerful questions to address deficiencies in pioneering and energizing approaches across the three primary components of the coaching conversation are listed in Table 2. These findings reveal areas for growth in the course curriculum. The ENGR 496 course requires coaches to complete assignments that generate powerful questions in preparation for team and coachee meetings as well as reflect on how the use of powerful questioning impacted these meetings. While this preparation is important, often coaches have to fashion questions on the spot based on the direction and lead of the coachee. Changes to the course curriculum should enhance recognition and understanding of the middle and end portion of the coaching conversation. Thinking of powerful questions in advance is good for preparation, however, students must also be able to recognize and apply appropriate powerful questions based on the lead or the direction of the coachee.

Table 2. Coaching Conversation and Powerful Question Examples

\begin{tabular}{|l|l|l|}
\hline $\begin{array}{l}\text { Clarifying Questions } \\
\text { (Beginning) }\end{array}$ & $\begin{array}{l}\text { Stretching Questions } \\
\text { (Middle) }\end{array}$ & $\begin{array}{l}\text { Action Item Questions } \\
\text { (End_ }\end{array}$ \\
\hline $\begin{array}{l}\text { What would you like to } \\
\text { accomplish? }\end{array}$ & $\begin{array}{l}\text { What might get in the way of } \\
\text { doing this? }\end{array}$ & $\begin{array}{l}\text { What are steps you can take } \\
\text { reach your goal? }\end{array}$ \\
\hline What have you tried so far? & $\begin{array}{l}\text { What if you did X, how } \\
\text { would you feel? }\end{array}$ & $\begin{array}{l}\text { How will you know you are } \\
\text { successful? }\end{array}$ \\
\hline $\begin{array}{l}\text { How do your actions help the } \\
\text { situation? }\end{array}$ & $\begin{array}{l}\text { If we could wipe the slate } \\
\text { clean what would you do? }\end{array}$ & What will you do? When? \\
\hline What does success look like? & $\begin{array}{l}\text { How does this relate to your } \\
\text { life's purpose? }\end{array}$ & $\begin{array}{l}\text { Where do you plan to go } \\
\text { from here? }\end{array}$ \\
\hline
\end{tabular}

The third and final interesting finding relates to the commanding approach. Specific to managerial coaching, as reflected in Table 1, low commanding behaviors are needed for transferring ownership to employees and holding back or not providing all the answers [34], [35]. Coaching requires that the coachee lead, therefore, lower observations of commanding behaviors may indicate that a coach refrains from taking charge, letting the coachee take ownership of their personal growth and development. Lower commanding scores for this study are interesting when considering the leadership style preferences of the ENGR 496 coaches. The Everything DiSC $363{ }^{\circledR}$ also provides a leadership preference through the self-assessed portion 
completed by the ENGR 496 coaches. Nine out of the 14 coaches reported a leadership style score in the dominance category which aligns with the commanding approach of the Everything DiSC $363^{\circledR}$ assessment. With preferred leadership styles aligning with a commanding approach, it is interesting that commanding was a lower rated behavior observed in the ENGR 496 coaches. However, while commanding approaches were rated lower, the commanding mean scores indicate that the approach is present in the coaches' behaviors and in close range with the other higher mean scores (see figure 2). The presence of commanding behaviors indicates a need to evaluate the current learning objectives and activities of the ENGR 496 course aimed at reducing commanding behaviors.

\section{Conclusion}

This study reflects on the curriculum of a course on coaching and observations of leaders who practiced coaching skills with engineering student teams and individual leaders. The findings are intended to explore the observed leadership behaviors in engineering leadership students practicing coaching skills. These findings help the instructors to consider where curricular changes are needed in order to improve the curriculum for future classes. Pioneering and energizing approaches were ranked the lowest from an observation of means from a 360feedback tool. Based on these findings, the course curriculum should be adjusted to impact students' knowledge and abilities in managerial coaching skills related to empowering and developing others. Future iterations of the course should include deeper knowledge and application of powerful questioning techniques and building confidence in conversations that stretch teams or individuals beyond current limitations. Commanding behaviors, typical in traditional notions of leadership, also need to be addressed more fully in the coaching course. The study findings are limited by the small sample size and therefore limit broad representation. Although the sample was low it provided insight for course improvement and iteration. Future research specific to this study should include a pre- and post-analysis of coaching skills with translation to a 360-leadership tool. Broader research into the impact of managerial coaching behaviors on engineering performance, knowledge transfer of managerial coaching training programs, and the impact of managerial coaching on creativity and innovation in engineering design are needed.

\section{References}

[1] D. Jonassen et al., "Everyday problem solving in engineering," J. Eng. Educ., vol. 9, no. 2, pp. 139-151, 2006.

[2] J. Orr, Talking about machines: An ethnography of a modern job. Ithaca, NY: IRL Press, 1996.

[3] M. Handley and C. . Berdanier, "Operationalizing interpersonal behaviours of leadership for early-career engineers," Int. J. Eng. Educ., vol. In Press, 2019.

[4] R. Agarwal, C. . Angst, and M. Magni, "The performance impacts of coaching: A multilevel analysis using hierarchical linear modeling," Int. J. Hum. Resour. Manag., vol. 20, no. 10, pp. 2110-2134, 2009.

[5] L. Ratiu, O. A. David, and A. Baban, "Developing Managerial Skills Through Coaching: Efficacy of a Cognitive-Behavioral Coaching Program," J. Ration. - Emotive Cogn. Behav. Ther., vol. 34, no. 4, pp. 244-266, 2016. 
[6] R. G. Hamlin, A. D. Ellinger, and R. S. Beattie, "Coaching at the heart of managerial effectiveness: A cross-cultural study of managerial behaviours," Hum. Resour. Dev. Int., vol. 9 , no. 3, pp. 305-331, 2006.

[7] D. . Peterson and M. D. Hicks, The leader as coach: Strategies for coaching and developing others. Minneapolis, MN, 1995.

[8] C. M. B. O'Flaherty and J. Everson, "Equipping Leaders To Coach - an Androgogic Learning Model," Elev. Int. East. Acad. Manag. Conf. Manag. a Glob. Econ., pp. 372397, 2005.

[9] J. . Hunt and J. . Weingraub, The coaching manager: Developing top talent in business. Thousand Oaks, CA: Sage, 2002.

[10] V. . Bianco-Mathis, L. . Nabos, and C. H. Roman, Leading from the inside out: A coaching model. Thousand Oaks, CA: Sage, 2002.

[11] A. D. Ellinger, A. E. Ellinger, and S. B. Keller, "Supervisory coaching behavior, employee satisfaction, and warehouse employee performance: A dyadic perspective in the distribution industry," Hum. Resour. Dev. Q., vol. 14, no. 4, pp. 435-458, 2003.

[12] A. D. Ellinger, A. E. Ellinger, D. G. Bachrach, Y. L. Wang, and A. B. E. Baş, "Organizational investments in social capital, managerial coaching, and employee workrelated performance," Manag. Learn., vol. 42, no. 1, pp. 67-85, 2011.

[13] P. King and J. Eaton, "Coaching for results," Ind. Commer. Train., vol. 31, no. 4, pp. 145$151,1999$.

[14] R. D. Evered and J. . Selman, "Coaching and the art of management," Organ. Dyn., vol. 18, pp. 16-32, 1989.

[15] F. F. Fournies, Coaching for improved work performance. Kansas City, MO: Liberty Hall Press, 1987.

[16] R. Hargrove, Masterful Coaching. San Francisco, CA: Pfeiffer, 1995.

[17] C. . Orth, H. E. Wilkinson, and R. C. Benfari, "The manager's role as coach and mentor," Organ. Dyn., pp. 66-74, 1987.

[18] A. E. Ellinger, A. Elmadag, and A. D. Ellinger, “An examination of organizations' frontline service employee development practices," Hum. Resour. Dev. Q., vol. 18, no. 3, pp. 293-314, 2007.

[19] B. B. Joo, J. S. Sushko, and G. N. Mclean, "Multiple faces of coaching: Manager-ascoach, executive coaching, and formal mentoring," Organ. Dev. J., vol. 30, no. 1, pp. 1938, 2012.

[20] Mclean N.G., Yang B., Kuo C.M., Tolbert S.A., and Larkin C., "Development and initial validation of an instrument measuring managerial coaching skill," Hum. Resour. Dev. Q., vol. 16, no. 2, pp. 157-178, 2005.

[21] C. Rottmann, R. Sacks, and D. Reeve, "Engineering leadership: Grounding leadership theory in engineers' professional identities," Leadership, vol. 11, no. 3, pp. 351-373, 2014.

[22] R. Sunindijo, B. Hadikusumo, and S. Ogunlana, "Emotional intelligence and leadership styles in construction project management," J. Manag. Eng., vol. 23, no. 4, pp. 166-170, 2007.

[23] M. E. Berg and J. T. Karlsen, "A study of coaching leadership style practice in projects," Manag. Res. Rev., vol. 39, no. 9, pp. 1122-1142, 2016.

[24] M. E. Derro and P. A. Trisha Jansma, "Coaching valuable systems engineering behaviors," IEEE Aerosp. Conf. Proc., 2008. 
[25] Y. Reich, G. Ullmann, M. Van Der Loos, and L. Leifer, "Coaching product development teams: A conceptual foundation for empirical studies," Res. Eng. Des., vol. 19, no. 4, pp. 205-222, 2009.

[26] C. J. Stettina, Z. Zhao, T. Back, and B. Katzy, "Academic education of software engineering practices: Towards planning and improving capstone courses based upon intensive coaching and team routines," Softw. Eng. Educ. Conf. Proc., no. May, pp. 169178, 2013.

[27] K. W. Jablokow, "Developing problem solving leadership : A cognitive approach *," Int. J. Eng. Educ., vol. 24, no. 5, pp. 936-954, 2008.

[28] A. Gilley, P. Dixon, and J. Gilley, "Characteristics of leadership effectiveness: Implementing change and driving innovation in organizations," Thai J. Math., vol. 15, no. 2, pp. 359-365, 2017.

[29] D. Knight, W. Poppen, J. E. Seat, J. Parsons, G. Klukken, and A. Glore, “Coaching Engineering Design Teams," 1997.

[30] D. Kolb, Experiential learning: Experience as the source of learning and development. Englewood Cliffs, NJ: Prentice Hall, 1984.

[31] E. Cox, T. Bachkirova, and D. Clutterbuck, The complete handbook of coaching. Thousand Oaks, CA: Sage, 2010.

[32] D. V Day, "Leadership development: A review in context," Leadersh. Q., vol. 11, no. 4, pp. 581-613, 2000.

[33] "Everything DiSC 363(R) for Leaders," 2016.

[34] A. D. Ellinger and R. P. Bostrom, "Managerial coaching behaviors in learning organizations," J. Manag. Dev., vol. 18, no. 9, pp. 752-71, 1999.

[35] R. S. Beattie, "Line managers as facilitators of learning: Empirical evidence from voluntary sector," in Human Resource Development and Research and Practice across Europe Conference, 2002. 